\title{
PERANCANGAN GEARBOX TRAKTOR TANGAN 2 KECEPATAN 1 MUNDUR DENGAN SISTEM PEMINDAH GIGI SYNCHROMESH
}

\author{
Bustami Ibrahim ${ }^{1}$, Aziza Noor Fadhila², Rofan Yulian Romansyah ${ }^{3}$ \\ ${ }^{1}$ Dosen Jur. Teknik Perancangan Manufaktur, Politeknik Manufaktur Negeri Bandung \\ Jl. Kanayakan 21 Bandung 40135 \\ email: bustami@polman-bandung.ac.id \\ ${ }^{2}$ Mahasiswa D4 Politeknik Manufaktur Negeri Bandung, Kons. Tek. Rekayasa dan Pengembangan \\ Produk \\ Jl. Kanayakan 21 Bandung 40135 \\ email: azizadila20@gmail.com \\ ${ }^{3}$ Dosen Jur. Teknik Perancangan Manufaktur, Politeknik Manufaktur Negeri Bandung \\ J1. Kanayakan 21 Bandung 40135 \\ email: rofanyr@polman-bandung.ac.id
}

\begin{abstract}
Abstrak
Saat ini Polman Bandung sedang melakukan pengembangan hand tractor atau traktor tangan melalui Pusat Pengembangan Power Train Otomotif (P3TO) dengan fokus kajian yang penting untuk dilakukan saat ini adalah perancangan gearbox baru untuk traktor tangan yang akan dikembangkan. Pengembangan-pengembangan yang akan dilakukan saat ini ialah penambahan kecepatan pada gearbox, peningkatan perfoma gearbox dan peningkatan kemudahan operasi dari gearbox yang dilihat dari segi sistem pemindah gigi yang ada pada gearbox. Hal ini didasarkan pada model-model gearbox pada traktor tangan yang ada di Indonesia, dinilai memiliki kekurangan pada aspek-aspek yang akan dikembangkan saat ini terutama pada jumlah kecepatan dan sistem pemindah giginya, maka dari itu pada tugas akhir ini dipilih multi speed gearbox dengan 2 kecepatan 1 mundur dengan sistem pemindah gigi synchromesh untuk mengatasi kekurangan-kekurangan gearbox traktor tangan yang ada saat ini. Tahapan perancangan dilakukan berdasarkan metode perancangan VDI 2222. Penelitian ini bertujuan untuk menghasilkan rancangan gearbox yang sesuai dengan daftar tuntutan dengan sistem dan performa yang lebih baik dari yang ada saat ini di pasaran.
\end{abstract}

Kata kunci : Traktor Tangan, Gearbox, Synchromesh, VDI 2222

\begin{abstract}
At the moment, Polman Bandung is developing a hand tractor through Pusat Pengembangan Power Train Otomotif (P3TO) with the focus of study in designing a new gearbox for hand tractor that will be developed. The developments that will be done at this time is the addition of speed on the gearbox, increased gearbox performance and increased ease of operation of the gearbox that can be viewed from gear shifting system in the gearbox. This is based on gearbox models on hand tractors in Indonesia, considered to have deficiencies in aspects that will be developed at this time, especially on the amount of speed and gear shifting system, therefore in this final project, multi speed gearbox with 2 speeds 1 reverse with a synchromesh gear shifting system have been selected to overcome the shortcomings of current hand tractor gearboxes. The design step is based on the design method of VDI 2222. This research aims to create a gearbox design that matches the list of demands desired which has better system and performance than existing on the market.
\end{abstract}

Keywords: Hand Tractor, Gearbox, Synchromesh, VDI 2222

14 Ibrahim, Bustami., dkk; Perancangan Gearbox Traktor Tangan 2 Kecepatan 1 Mundur Dengan Sistem Pemindah Gigi Synchromesh 


\section{PENDAHULUAN}

Saat ini Polman Bandung sedang melakukan pengembangan hand tractor melalui Pusat Pengembangan Power Train Otomotif (P3TO) dengan fokus kajian yang penting untuk dilakukan saat ini adalah perancangan gearbox baru untuk traktor tangan yang akan dikembangkan.

Pengembangan-pengembangan yang akan dilakukan saat ini ialah penambahan kecepatan pada gearbox, peningkatan perfoma gearbox dan peningkatan kemudahan operasi dari gearbox yang dilihat dari segi sistem pemindah gigi yang ada pada gearbox. Sebagai acuan dalam melakukan pengembangan spesifikasi gearbox, digunakan satu referensi model traktor yang memiliki spesifikasi yang mendekati dengan spesifikasi gearbox yang diinginkan yaitu Quick M 1000 Alfa.

Sebagai tahap akhir dari pengembangan, maka dilakukan pengkajian terhadap kemampuan gearbox yang telah dirancang dari segi kekuatan komponen-komponen pendukungnya dan ketercapaiannya terhadap daftar tuntutan yang diinginkan.

Adapun tujuan dari tugas akhir ini adalah menghasilkan rancangan gearbox yang dapat memenuhi daftar tuntutan yang diberikan dan menghasilkan dokumentasi teknik berupa draft dari rancangan gearbox yang telah dibuat.

\section{METODE PENELITIAN}

Metode perancangan yang digunakan pada tugas akhir ini adalah VDI 2222 dengan alur penyelesaian seperti pada Gambar 1 .

\section{Tahap Merencana}

Pada tahap ini, dilakukan pengumpulan data-data referensi yang dapat mendukung penelitian penulis. Selanjutnya, data-data ini dirubah menjadi daftar tuntutan untuk rancangan yang akan dirancang. Menetapkan Daftar Tuntutan seperti pada tabel 1.

\section{Tabel 1 Daftar Tuntutan}

\begin{tabular}{|c|c|c|c|c|c|}
\hline \multicolumn{6}{|c|}{ Tuntutan Primer } \\
\hline No & $\begin{array}{c}\text { Daftar } \\
\text { Tuntutan }\end{array}$ & \multicolumn{4}{|c|}{ Spesifikasi } \\
\hline \multirow[t]{4}{*}{1.} & \multirow{4}{*}{$\begin{array}{l}\text { Penggerak } \\
\text { (Engine) }\end{array}$} & \multicolumn{4}{|c|}{ Kubota RD 65 DI-2S } \\
\hline & & $\begin{array}{l}\text { Daya } \\
\text { maksimum }\end{array}$ & $\mathrm{P}$ & 6.5 & $\mathrm{HP}$ \\
\hline & & $\begin{array}{l}\text { RPM saat daya } \\
\text { maksimum }\end{array}$ & $\mathrm{n}$ & 2200 & $\mathrm{rpm}$ \\
\hline & & $\begin{array}{l}\text { Torsi } \\
\text { maksimum }\end{array}$ & $\mathrm{T}_{\mathrm{m}}$ & 2.36 & kg.m \\
\hline
\end{tabular}

\begin{tabular}{|c|c|c|c|}
\hline \multicolumn{4}{|c|}{ Tuntutan Primer } \\
\hline No & \multicolumn{3}{|c|}{ Spesifikasi } \\
\hline & $\begin{array}{l}\text { RPM saat torsi } \\
\text { maksimum }\end{array}$ & $\mathrm{n}_{\mathrm{m}}$ & $\mathrm{rpm}$ \\
\hline \multirow[t]{4}{*}{2.} & Kecepatan & \multicolumn{2}{|c|}{2 Kecepatan 1 Mundur } \\
\hline & Kecepatan 1 & $\mathrm{v}_{1}$ & $\mathrm{~km} / \mathrm{jam}$ \\
\hline & Kecepatan 2 & $v_{2}$ & $\mathrm{~km} / \mathrm{jam}$ \\
\hline & Mundur & $v_{R}$ & $\mathrm{~km} / \mathrm{jam}$ \\
\hline 3. & \multicolumn{3}{|c|}{ Spur Gear } \\
\hline \multicolumn{4}{|c|}{ Tuntutan Sekunder } \\
\hline No. & Daftar Tuntutan & \multicolumn{2}{|c|}{ Spesifikasi } \\
\hline 1. & Berat gearbox & \multicolumn{2}{|c|}{$\leq 150 \mathrm{~kg}$} \\
\hline 2. & $\begin{array}{l}\text { Jarak poros input dan } \\
\text { output gearbox }\end{array}$ & \multicolumn{2}{|c|}{$\leq 450 \mathrm{~mm}$} \\
\hline 3. & Dimensi total & \multicolumn{2}{|c|}{$\begin{array}{c}\text { Lebih kecil dari } \\
350 \times 650 \times 650 \mathrm{~mm}\end{array}$} \\
\hline \multicolumn{4}{|c|}{ Tuntutan Tertier } \\
\hline & Keinginan & \multicolumn{2}{|c|}{ Keterangan } \\
\hline 1. & $\begin{array}{l}\text { Pemindahan gigi yang } \\
\text { sederhana dan halus }\end{array}$ & $\begin{array}{l}\text { Digur } \\
\text { pemir } \\
\text { meka } \\
\text { cone }\end{array}$ & $\begin{array}{r}\text { sistem } \\
\text { dengan } \\
\text { clutch }+ \\
\text { gearbox }\end{array}$ \\
\hline
\end{tabular}

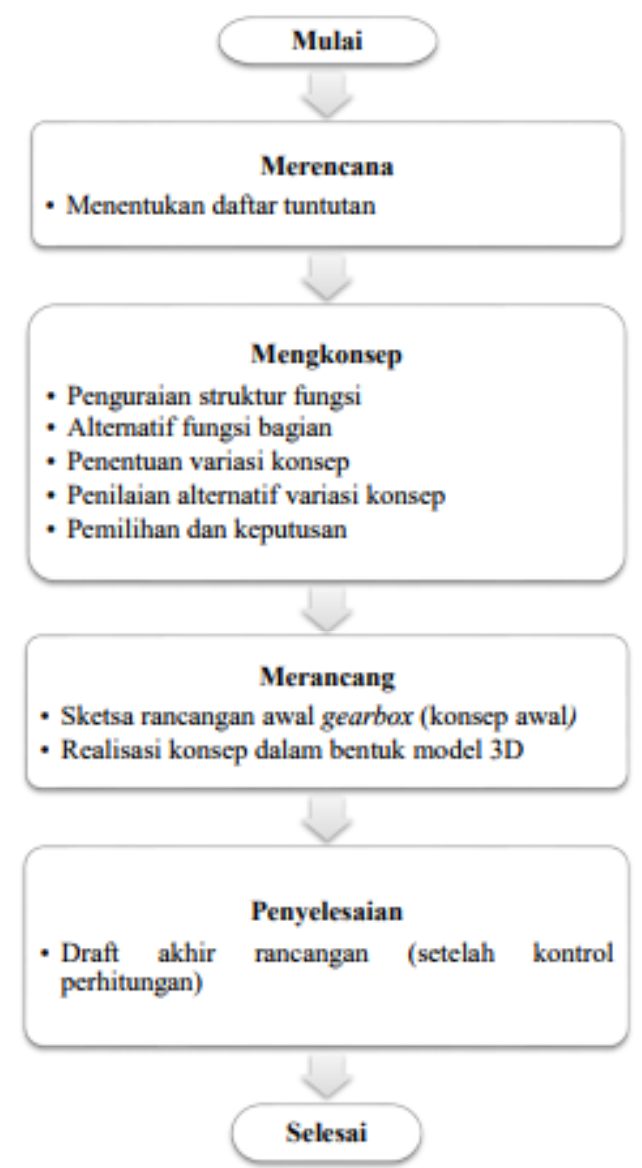

Gambar 1 Metode Perancangan Gearbox Traktor Tangan 2 Kecepatan 1 Mundur 


\section{Tahap Mengkonsep}

- Penguraian Struktur Fungsi

Mengacu pada model referensi yang ada yaitu Quick M 1000 Alfa, maka dapat dibuat suatu blackbox rancangan yang memuat seluruh fungsi bagian yang terdapat dalam gearbox. Berikut adalah blackbox rancangan tersebut seperti tergambar pada gambar 2 .

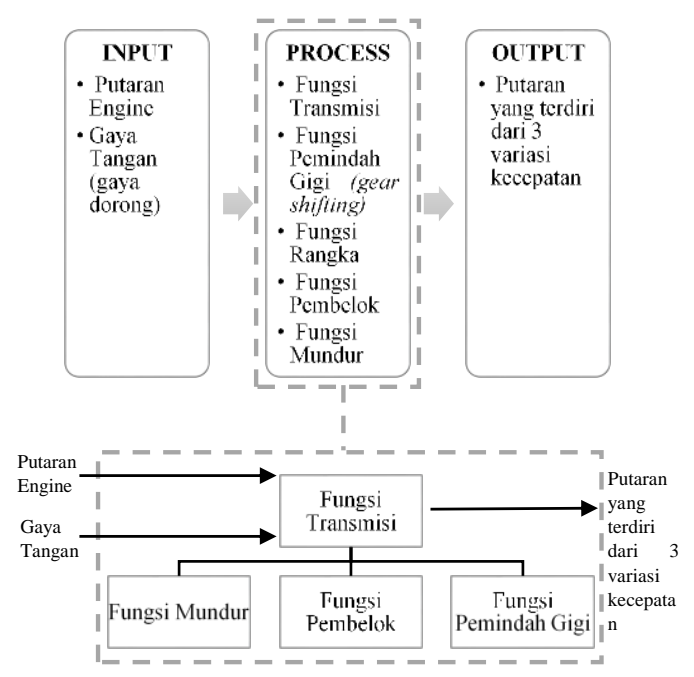

Gambar 2 Blackbox Rancangan

Berdasarkan black box tersebut, maka dihasilkan beberapa fungsi bagian pada Gambar 3.

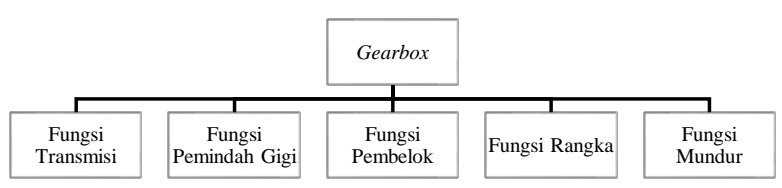

Gambar 3 Diagram Fungsi Bagian

- Alternatif Fungsi Bagian

Setelah fungsi bagian ditentukan, selanjutnya didefinisikan sehingga menghasilkan beberapa alternatif fungsi bagian. Alternatif fungsi bagian ini, nantinya akan digabungkan satu sama lain sehingga terbentuk beberapa alternatif variasi konsep. Berikut adalah salah satu alternatif fungsi bagian yang penulis buat seperti pada Tabel 2.
Tabel 2 Alternatif Fungsi Rangka

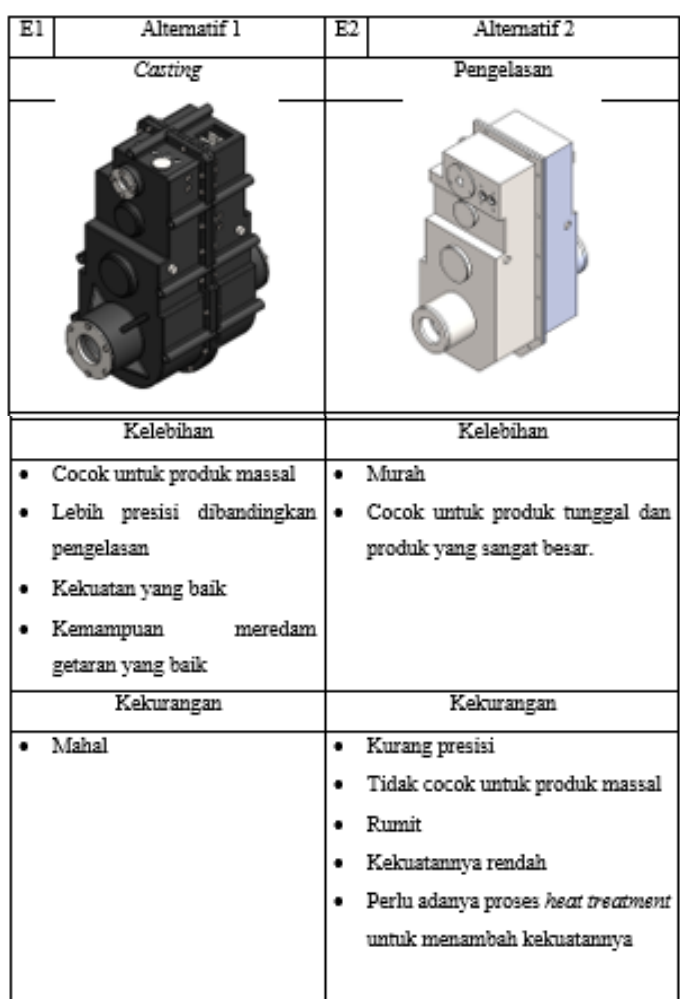

Hal yang sama juga dilakukan pada fungsi bagian pembelok dan pemindah gigi.

- Penentuan Variasi Konsep

Dari alternatif-alternatif fungsi bagian yang digabungkan satu sama lain, diperoleh tiga alternatif variasi konsep, seperti yang tercantum pada Tabel 3.

\section{Tabel 3 Kotak Morfologi}

\begin{tabular}{|c|l|c|c|c|}
\hline \multirow{2}{*}{ No. } & \multirow{2}{*}{ Fungsi Bagian } & \multicolumn{3}{|c|}{ Alternatif } \\
\cline { 3 - 4 } & & Alternatif 1 & Alternatif 2 & Altenatif 3 \\
\hline 1 & Fungsi Transmisi & \multicolumn{2}{|c|}{ A1 } & \multirow{2}{*}{} \\
\hline 2 & Fungsi Mundur & \\
\hline 2 & Fungsi Pemindah Gigi & C1 & C2 & \\
\hline 3 & Fungsi Pembelok & D1 & D2 & \\
\hline 4 & Fungsi Rangka & E1 & E2 & VK3 \\
\hline \multicolumn{2}{|l|}{ Variasi Konsep } & VK1 & VK2 & VK \\
\hline
\end{tabular}

- Penilaian Variasi Konsep

Selanjutnya, masing-masing alternatif variasi konsep dinilai berdasarkan beberapa aspek yang diantaranya pencapaian fungsi-fungsi konstruksi, pembuatan, kemudahan perakitan, pengoperasian dan kemudahan perawatan.

\section{Pemilihan dan Keputusan}

Berdasarkan penilaian pada beberapa aspek yang tercantum sebelumnya, maka dipilih alternatif 1 
karena alternatif ini memiliki nilai yang lebih tinggi dari alternatif lainnya.

\section{Tahap Merancang}

- Realisasi Konsep dalam Model 3D

Mengacu pada sketsa konsep yang penulis pilih, berikut adalah hasil realisasinya dalam bentuk modelling 3D menggunakan software Solidworks.

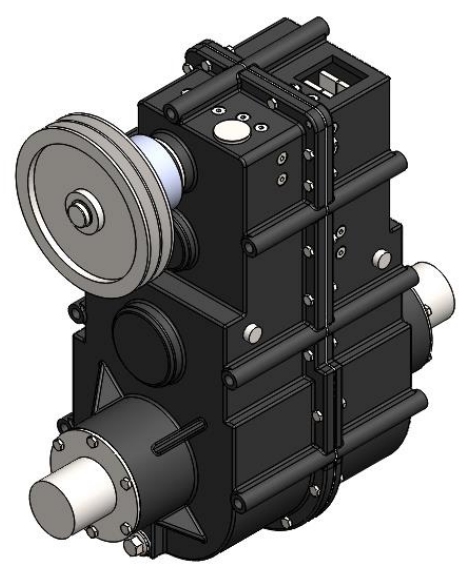

Gambar 4 Model 3D

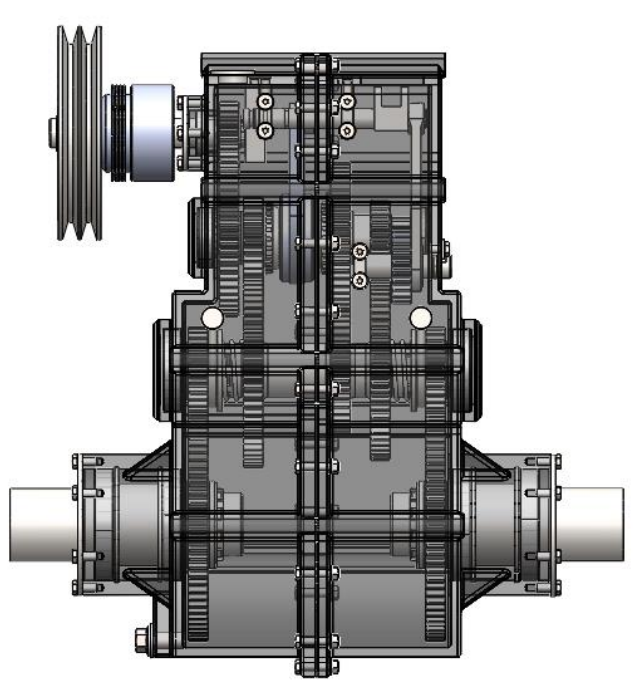

Gambar 5 Model 3D Pandangan Depan

\section{HASIL DAN PEMBAHASAN}

\section{Perhitungan Rasio Gearbox}

Perhitungan rasio gearbox dilakukan berdasarkan torsi maksimum engine, dikarenakan traktor hanya akan bekerja pada rpm yang rendah untuk menghasilkan kualitas rol yang lebih baik. Pada Tabel 4 adalah perhitungan rasio gearbox yang telah dilakukan.

\section{Tabel 4 Rasio Gearbox}

\begin{tabular}{|c|c|c|c|c|}
\hline Simbol & Variabel & Nilai & Satuan & Rumus / Sumber \\
\hline $\mathrm{T}_{\mathrm{s}}$ & Torsi maksimum engine & 23.152 & $\mathrm{Nm}$ & spesifikasi engine \\
\hline $\mathrm{n}_{\mathrm{s}}$ & $\begin{array}{l}\text { Rpm engine saat torsi } \\
\text { maksimum }\end{array}$ & 1500 & $\mathrm{rpm}$ & spesifikasi engine \\
\hline$i_{8}$ & Rasio Puli & 2.2 & & Quick Impala \\
\hline $\mathrm{v}_{1}$ & Kecepatan 1 & 5 & $\mathrm{~km} / \mathrm{jam}$ & spesifikasi gearbox \\
\hline $\mathrm{v}_{1}$ & Kecepatan 2 & 15 & $\mathrm{~km} / \mathrm{jam}$ & spesifikasi gearbox \\
\hline$v_{\mathrm{R}}$ & Kecepatan mundur & 5 & $\mathrm{~km} / \mathrm{jam}$ & spesifikasi gearbox \\
\hline $\mathrm{D}$ & Diameter Roda & 700 & $\mathrm{~mm}$ & spesifikasi gearbox \\
\hline $\mathrm{n}_{\mathrm{s} !}$ & Rpm output kondisi 1 & 37.894 & rpm & $n_{1}=\frac{2 \cdot v_{1}}{D}$ \\
\hline$n_{52}$ & Rpm output kondisi 2 & 113.682 & rem & $n_{2}=\frac{2 \cdot v_{2}}{D}$ \\
\hline $\mathrm{n}_{\mathrm{8} 3}$ & $\begin{array}{l}\text { Rpm output kondisi } 3 \\
\text { (mundur) }\end{array}$ & 37.894 & $\mathrm{rpm}$ & $n_{3}=\frac{2 \cdot v_{R}}{D}$ \\
\hline $\mathbf{i}_{z_{1}}$ & Rasio gearbox kondisi l & 17.993 & & $i_{g 1}=\frac{n_{g}}{n_{1}, i_{p}}$ \\
\hline $\mathbf{i}_{2^{2}}$ & Rasio gearbox kondisi 2 & 5.998 & & $i_{g 2}=\frac{n_{e}}{n_{2} \cdot i_{p}}$ \\
\hline $\mathbf{i}_{2^{3}}$ & Rasio gearbox kondisi 3 & 17.993 & & $i_{g 3}=\frac{n_{e}}{n_{3} \cdot i_{p}}$ \\
\hline
\end{tabular}

\section{Perhitungan Tingkat Transmisi}

Berdasarkan hasil perhitungan dan pertimbangan desain, dipilih gearbox dengan tingkat transmisi 3 dengan layout multi stage gearbox.

\section{Perhitungan Pasangan Roda Gigi}

Dalam gearbox ini, terdapat 11 roda gigi, berikut adalah salah satu contoh perhitungan kekuatan roda gigi yang dilakukan yang terdapat pada tabel 5 dan tabel 6.

\section{Tabel 5 Tegangan Kaki Gigi}

\begin{tabular}{|c|c|c|c|c|}
\hline \multicolumn{5}{|c|}{ Tegangan Kaki Gigi - Roda Gigi 1} \\
\hline Simbol & Variabel & Nilai & Satuan & Keterangan \\
\hline $\mathrm{K}_{\mathrm{A}}$ & Faktor kerja & 1.75 & & $\begin{array}{l}\text { motor bakar dengan hentakan } \\
\text { menengah }\end{array}$ \\
\hline $\mathrm{n}_{1}$ & Rpm poros 1 & 681.82 & $\mathrm{rpm}$ & $n_{1}=\frac{n_{e}}{i_{-}}$ \\
\hline $\mathrm{T}_{1}$ & \begin{tabular}{|l|} 
Torsi pada roda gigi 1 \\
\end{tabular} & 89.134 & $\mathrm{Nm}$ & $T_{1}=T_{e}, K_{A} \cdot i_{p}$ \\
\hline$F_{t 1}$ & $\begin{array}{l}\text { Gaya tangensial roda } \\
\text { gigi } 1\end{array}$ & 2971.13 & $\mathrm{~N}$ & $F_{t}=\frac{2 . T}{d^{2}}$ \\
\hline$F_{r 1}$ & \begin{tabular}{|l} 
Gaya radial roda gigi 1 \\
\end{tabular} & 1081.4 & $\mathrm{~N}$ & $F_{r}=F_{r} \cdot \tan (\alpha)$ \\
\hline $\mathrm{K}_{\mathrm{r}}$ & \begin{tabular}{|l|} 
Faktor dinamis \\
\end{tabular} & 1.196 & & \\
\hline $\mathrm{K}_{\text {HP }}$ & Faktor lebar diatas kaki & 1.482 & & \\
\hline $\mathrm{K}_{F_{\beta}}$ & Faktor lebar kaki & 1.312 & & \\
\hline $\mathrm{K}_{F_{a}}$ & \begin{tabular}{|l} 
Faktor defleksi \\
\end{tabular} & 0.889 & & \\
\hline $\mathrm{K}_{\mathrm{Ha}}$ & \begin{tabular}{|l} 
Faktor defleksi \\
\end{tabular} & 0.889 & & \\
\hline $\mathrm{K}_{\mathrm{Fgos}}$ & $\begin{array}{l}\text { Faktor keseluruhan } \\
\text { pembebanan tegangan } \\
\text { kaki gigi }\end{array}$ & 2.441 & & $K_{F g e s}=K_{A} \cdot K_{v} \cdot K_{F \beta} \cdot K_{F \alpha}$ \\
\hline $\mathrm{Y}_{\overline{T_{2}}}$ & \begin{tabular}{|l|} 
Faktor bentuk \\
\end{tabular} & 2.9 & & \\
\hline $\mathrm{Y}_{\mathrm{sa}}$ & $\begin{array}{|ll|}\begin{array}{l}\text { Faltor } \\
\text { tegangan }\end{array} & \text { koreksi } \\
\end{array}$ & 1.6 & & jumlah gigi $\mathrm{z}_{1}$ tanpa koreksi \\
\hline $\mathrm{Y}_{z}$ & Faktor rasio kontak & 0.702 & & $Y_{x}=0,25+\left(\frac{0,75}{\varepsilon_{g}}\right)$ \\
\hline $\mathrm{Y}_{\beta}$ & \begin{tabular}{|l|} 
Faktor kemiringan \\
\end{tabular} & 1 & & $\beta=0^{\circ}$ \\
\hline Gro & Tegangan kaki lokal & 161.308 & $\frac{\mathrm{N}}{\mathrm{mm}^{2}}$ & $\sigma_{F a}=\frac{F_{t}}{m \cdot b} \cdot Y_{F a} \cdot Y_{s a} \cdot Y_{\varepsilon} \cdot Y_{\beta}$ \\
\hline$\sigma_{\mathrm{F}}$ & $\begin{array}{|ll|}\text { Tegangan } & \text { kaki } \\
\text { sesungguhnya }\end{array}$ & 393.73 & $\frac{\mathrm{N}}{\mathrm{mm}^{2}}$ & $\sigma_{F}=\sigma_{F 0} \cdot K_{\text {Fges }}$ \\
\hline $\mathrm{Y}_{\mathrm{NT}}$ & Faktor umur harapan & 1.9 & & umur harapan $10000 \mathrm{jam}$ \\
\hline$Y_{x}$ & Faktor modul/lebar & 1 & & $\mathrm{~m}<5$ \\
\hline$\sigma_{\mathrm{Flim}}$ & Tegangan ijin bahan & 370 & $\frac{\mathrm{N}}{\mathrm{mm}^{2}}$ & bahan $\mathrm{C} 45 \mathrm{E}$ \\
\hline GFG & $\begin{array}{l}\text { Kemampuan tegangan } \\
\text { kaki gigi }\end{array}$ & 1406 & $\frac{\mathrm{N}}{\mathrm{mm}^{2}}$ & $\sigma_{F 0}=2 \cdot \sigma_{\text {Flim }} \cdot Y_{N T} \cdot Y_{x}$ \\
\hline $\mathrm{S}_{\mathrm{F}}$ & Safety Factor & 3.57 & & $S F=\frac{\sigma_{F G}}{\sigma_{F}} \geq(1) \ldots 1.6$ \\
\hline
\end{tabular}


Tabel 6 Tekanan Permukaan Kaki Gigi

\begin{tabular}{|c|c|c|c|c|}
\hline \multicolumn{5}{|c|}{ Tekanan Permukaan Kaki Gigi - Roda Gigi l } \\
\hline Simbol & Variabel & Nilai & Satuan & Keterangan \\
\hline $\mathrm{K}_{\text {Hges }}$ & $\begin{array}{l}\text { Faktor keseluruh } \\
\text { pembebanan tekanan } \\
\text { permukaan }\end{array}$ & 1.661 & & $K_{\text {Hges }}=\sqrt{K_{A} \cdot K_{v} \cdot K_{F \beta} \cdot K_{F \alpha}}$ \\
\hline $\mathrm{Z}_{\mathrm{H}}$ & Faktor zona/daerah & 2.5 & & $\begin{array}{l}\text { untuk roda gigi lurus tanpa } \\
\text { koreksi }\end{array}$ \\
\hline$Z_{E}$ & Faktor elastisitas & 189.8 & $\sqrt{\frac{\mathrm{N}}{\mathrm{mm}^{2}}}$ & untuk kelompok baja \\
\hline$Z_{\varepsilon}$ & Faktor rasio kontak & 0.883 & & $Z_{\varepsilon}=\sqrt{\left(4-\varepsilon_{\alpha)} / 3\right.}$ \\
\hline $\mathrm{OHO}_{\mathrm{H}}$ & $\begin{array}{l}\text { Tekanan permukaan } \\
\text { lokal }\end{array}$ & 776.35 & $\frac{\mathrm{N}}{\mathrm{mm}^{2}}$ & $\sigma_{H 0}=z_{\varepsilon}, z_{\beta} \cdot z_{u} \cdot z_{E} \cdot \sqrt{\frac{F_{t}}{m \cdot b} \frac{u+1}{u}}$ \\
\hline$\sigma_{\mathrm{H}}$ & $\begin{array}{l}\text { Tekanan permukaan } \\
\text { sesungguhnya }\end{array}$ & 1289.48 & $\frac{\mathrm{N}}{\mathrm{mm}^{2}}$ & $\sigma_{H}=\sigma_{H 0} \cdot K_{\text {Hges }}$ \\
\hline OFlim & $\begin{array}{l}\text { Tekanan permukaan } \\
\text { ijin bahan }\end{array}$ & 1220 & $\frac{\mathrm{N}}{\mathrm{mm}^{2}}$ & bahan $\mathrm{C} 45 \mathrm{E}$ \\
\hline $\mathrm{ZL}_{\mathrm{L}}$ & Faktor pelumas & 1.145 & & SAE 140 \\
\hline$Z_{v}$ & Faktor kecepatan & 1 & & untuk kecepatan $\mathrm{v}_{1}$ \\
\hline$Z_{R}$ & $\begin{array}{l}\text { Faktor kekasaran } \\
\text { permukaan }\end{array}$ & 0.91 & & $\mathrm{R}_{z}=10 \mu \mathrm{m}$ \\
\hline$Z_{\mathbb{w}}$ & \begin{tabular}{|l|}
$\begin{array}{l}\text { Faktor pasangan } \\
\text { bahan }\end{array}$ \\
\end{tabular} & 1 & & $\mathrm{HB}>400$ \\
\hline $\mathrm{Zx}$ & Faktor ukuran modul & 1 & & $\mathrm{~m}<8$ \\
\hline $\mathrm{Z}_{\mathrm{MI}}$ & \begin{tabular}{|l|} 
Faktor umur harapan \\
\end{tabular} & 1.6 & & umur harapan $1000 \mathrm{jam}$ \\
\hline OHG & \begin{tabular}{|l|}
$\begin{array}{l}\text { Kemampuan tekanann } \\
\text { permukaan kaki gigi }\end{array}$ \\
\end{tabular} & 2045.88 & $\frac{\mathrm{N}}{\mathrm{mm}^{2}}$ & $\sigma_{\text {HG }}=\sigma_{\text {Hitim }}, z_{N T} \cdot z_{L} \cdot z_{v}, z_{R} \cdot z_{W} \cdot z_{X}$ \\
\hline $\mathrm{S}_{\mathrm{H}}$ & Safety Factor & 1.56 & & $S H=\frac{\sigma_{H G}}{\sigma_{H}} \geq(1) \ldots 1,3$ \\
\hline
\end{tabular}

\section{Perhitungan Poros}

Pada gearbox ini terdapat 5 poros yang masing-masing dihitung kekuatannya, perhitungan yang dilakukan diantaranya defleksi bengkok, defleksi puntir, putaran kritis dan safety factor statis dan dinamis..
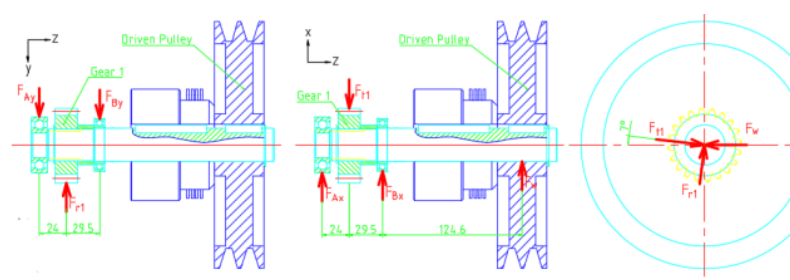

\section{Gambar 6 Diagram Benda Bebas Poros 1}

1. Defleksi Bengkok

Untuk poros 1, terdapat dua komponen yang menyebabkan defleksi yaitu puli dan roda gigi. Defleksi puli dan roda gigi dihitung secara terpisah, lalu dijumlahkan pada titik-titik yang sama, berikut adalah salah satu perhitungan defleksi yang telah dilakukan pada tabel 7 .

2. Defleksi Puntir

Defleksi puntir hanya dilakukan pada poros yang mengalami puntiran saja seperti poros 1 . Berikut adalah contoh perhitungan defleksi puntir yang penulis lakukan pada tabel 8 .
Tabel 7 Defleksi Bengkok

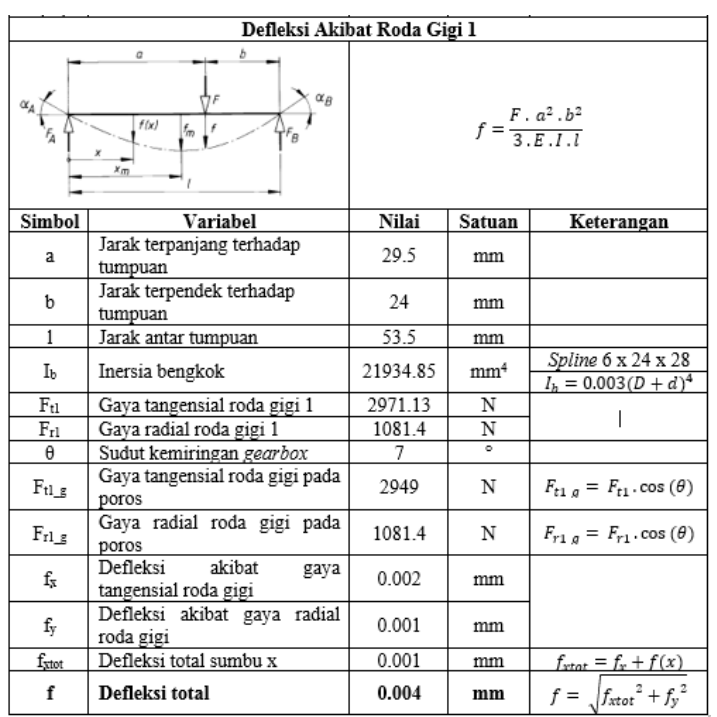

Tabel 8 Defleksi Puntir

\begin{tabular}{|c|l|c|c|c|}
\hline Simbol & \multicolumn{1}{|c|}{ Variabel } & Nilai & Satuan & Keterangan \\
\hline $\mathrm{T}_{1}$ & Torsi pada poros 1 & 89.134 & $\mathrm{Nm}$ & \\
\hline \multirow{2}{*}{$\mathrm{I}_{\mathrm{t}}$} & Inersia puntir & 79521 & $\mathrm{~mm}^{4}$ & $\mathrm{~d}=30 \mathrm{~mm}$ \\
\cline { 4 - 5 } & & & & $\mathrm{I}_{\mathrm{t}}=\frac{\pi}{32} \cdot d^{4}$ \\
\hline $\mathrm{G}$ & Modulus Geser & 81000 & $\frac{\mathrm{N}}{\mathrm{mm}^{2}}$ & untuk baja \\
\hline 1 & Panjang puntir & 154.1 & $\mathrm{~mm}$ & \\
\hline$\varphi$ & Sudut defleksi puntir & $\mathbf{0 . 0 0 2}$ & $\circ$ & \\
\hline
\end{tabular}

3. Putaran Kritis

Putaran kritis digunakan untuk memastikan putaran poros masih aman atau tidak akibat adanya defleksi bengkok pada poros. Perhitungan putaran kritis didasarkan pada defleksi bengkok maksimum yang terjadi tanpa melibatkan massa dari elemen-elemen yang menyebabkan defleksi.

\section{Tabel 9 Putaran Kritis}

\begin{tabular}{|c|l|c|c|c|}
\hline Simbol & \multicolumn{1}{|c|}{ Variabel } & Nilai & Satuan & Keterangan \\
\hline $\mathrm{k}$ & Factor koreksi & 1 & & \\
\hline $\mathrm{f}$ & Defleksi bengkok total & 0.003 & $\mathrm{~mm}$ & \\
\hline $\mathrm{n}_{\mathrm{k}}$ & Putaran kritis & 15073.35 & $\min ^{-1}$ & $n_{k} \approx k .946 \sqrt{\left(\frac{1}{f}\right)}$ \\
\hline
\end{tabular}

4. Safety Factor

Perhitungan safety factor bertujuan untuk menganalisis lokasi-lokasi kritis tertentu pada poros, apakah aman digunakan atau tidak. 
Tabel 10 Safety Factor Statis

\begin{tabular}{|c|c|c|c|c|}
\hline \multicolumn{5}{|c|}{ STATIS } \\
\hline Simbol & Variabel & Nilai & Satuan & Keterangan \\
\hline $\mathrm{x}$ & Jarak potongan & 154.1 & $\mathrm{~mm}$ & \\
\hline $\mathrm{M}_{\mathrm{bx}}$ & $\begin{array}{l}\text { Momen bengkok sumbu } \\
\mathrm{x}\end{array}$ & 59837 & $\mathrm{Nmm}$ & Software MDSolids \\
\hline $\mathrm{M}_{b_{y}}$ & $\begin{array}{l}\text { Momen bengkok sumbu } \\
\text { y }\end{array}$ & 14730.5 & $\mathrm{Nmm}$ & Software MDSolids \\
\hline $\mathrm{M}_{\mathrm{b}}$ & $\begin{array}{l}\text { Momen bengkok } \\
\text { gabungan }\end{array}$ & 61623.5 & $\mathrm{Nmm}$ & $M_{b}=\sqrt{M_{b x}{ }^{2}+M_{b y}{ }^{2}}$ \\
\hline$\frac{d}{D}$ & Penampang potongan & $\frac{24}{28}$ & $\mathrm{~mm}$ & Penampang Spline \\
\hline $\mathrm{W}_{\mathrm{b}}$ & $\begin{array}{ll}\text { Momen } & \text { tahanan } \\
\text { bengkok } & \end{array}$ & 1687.29 & $\mathrm{~mm}^{3}$ & $W_{b}=0,012(D+d)^{3}$ \\
\hline$\sigma_{b \max }$ & $\begin{array}{l}\text { Tegangan bengkok } \\
\text { maksimum }\end{array}$ & 36.5 & $\frac{\mathrm{N}}{\mathrm{mm}^{2}}$ & $\sigma_{b}=\frac{M_{b}}{W_{b}}$ \\
\hline $\mathrm{T}_{1}$ & Torsi yang terjadi & 89.13 & $\mathrm{Nm}$ & \\
\hline $\mathrm{W}_{\mathrm{t}}$ & Momen tahanan puntir & 3374.59 & $\mathrm{~mm}^{3}$ & $W_{t}=0,024 \cdot(D+d)^{3}$ \\
\hline$\tau_{\max }^{\max }$ & $\begin{array}{l}\text { Tegangan } \\
\text { maksimum }\end{array}$ & 26.413 & $\frac{\mathrm{N}}{\mathrm{mm}^{2}}$ & $\tau_{t}=\frac{T}{W_{t}}$ \\
\hline & $\mathrm{R}_{\mathrm{mN}}$ & 900 & \multirow{4}{*}{$\frac{\mathrm{N}}{\mathrm{mm}^{2}}$} & \multirow{4}{*}{ Bahan $20 \mathrm{MoCr} 4$} \\
\hline & $\mathrm{R}_{\mathrm{p} 0,2}$ & 630 & & \\
\hline & $\sigma_{b \pi N}$ & 675 & & \\
\hline & $\tau_{\text {bus }}$ & 435 & & \\
\hline $\mathrm{K}_{\mathrm{t}}$ & Faktor teknologi & 0.834 & & $K_{\mathrm{t}}=1-0,41 \cdot \log \left(\frac{d}{11 \mathrm{~mm}}\right)$ \\
\hline$\sigma_{b F}$ & \multirow[b]{2}{*}{ Kemampuan bahan } & 630.23 & \multirow{2}{*}{$\frac{\mathrm{N}}{\mathrm{mm}^{2}}$} & $\sigma_{b F}=1,2 \cdot R_{p 0,2} \cdot K_{t}$ \\
\hline$\tau_{U_{F}}$ & & 363.86 & & $\tau_{t F}=\frac{1,2 \cdot R_{p 0,2} \cdot K_{t}}{\sqrt{3}}$ \\
\hline $\mathrm{S}_{\mathrm{F}}$ & Safety Factor Statis & 10.76 & \multicolumn{2}{|c|}{$S_{F}=\frac{1}{\sqrt{\left(\frac{\sigma_{\max x}}{\sigma_{b F}}\right)^{2}+\left(\frac{\tau_{\operatorname{cmax}}}{\tau_{t F}}\right)^{2}}} \geq 1,5$} \\
\hline
\end{tabular}

Tabel 11 Safety Factor Dinamis

\begin{tabular}{|c|c|c|c|c|}
\hline \multicolumn{5}{|c|}{ DINAMIS } \\
\hline$\sigma_{\mathrm{ba}}$ & $\begin{array}{l}\text { Tegangam bengrok } \\
\text { dinamis }\end{array}$ & 36.52 & \multirow{2}{*}{$\frac{\mathrm{N}}{\mathrm{mm}^{2}}$} & $\sigma_{\mathrm{ba}}=\sigma_{\operatorname{lngax}}$ \\
\hline$\tau_{a}$ & $\begin{array}{l}\text { Tegangan puntir } \\
\text { dinamis }\end{array}$ & 26.413 & & $\tau_{\text {tan }}=\tau_{\text {terax }}$ \\
\hline & 750.27 & \multirow{3}{*}{$\frac{\frac{\mathrm{N}}{\mathrm{mm}^{2}}}{\mu \mathrm{m}}$} & $\frac{t_{\mathrm{tan}}=T_{\text {traur }}}{R_{\mathrm{m}}=K_{t} \cdot R_{\mathrm{mex}}}$ \\
\hline & 525.19 & & $K_{p}=K_{t} \cdot K_{n 0,2}$ \\
\hline$R_{x}$ & Kekasaren permukam & 10 & & \\
\hline \multicolumn{3}{|c|}{$K_{\mathrm{ar}}=1-0,22 \cdot \lg \left(R_{z}\right) \cdot\left(\lg \left(\frac{R_{m}}{20}\right)-1\right)=0,656$} & & \\
\hline \multicolumn{5}{|c|}{ 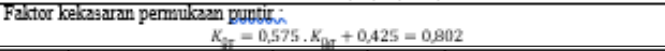 } \\
\hline 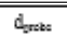 & Diameter pengujian & 29 & $\mathrm{~mm}$ & \\
\hline $\mathrm{d}$ & Diameter kritis poros & 28 & $\mathrm{~mm}$ & \\
\hline$\beta_{\text {hereses }}$ & $\begin{array}{l}\text { Faktor lokasi laritis } \\
\text { bengkok (uji) }\end{array}$ & 1.75 & & Berdasarkan nilai $\mathrm{Rm}$ \\
\hline \multicolumn{5}{|c|}{ 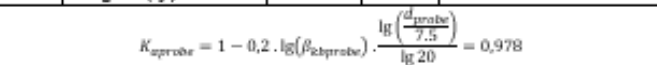 } \\
\hline \multicolumn{5}{|c|}{$K_{\alpha}=1-0,2 \cdot \lg \left(\beta_{\text {lappratar }}\right) \cdot \frac{\lg \left(\frac{d}{7.5}\right)}{\lg 20}=0,98$} \\
\hline$\beta_{n a}$ & $\begin{array}{l}\text { Faktor lokasi liritis } \\
\text { bengkok }\end{array}$ & 1.746 & & $\beta_{\text {ka }}=\beta_{\text {beppote }} \cdot \frac{K_{\text {aprabe }}}{K_{\alpha}}$ \\
\hline Prosecse & $\begin{array}{l}\text { Falktor lokasi laritis } \\
\text { puntir (uji) }\end{array}$ & 2 & & \\
\hline \multicolumn{5}{|c|}{$K_{\text {aprate }}=1-0,2 \cdot \lg \left(\beta_{\text {atppoute }}\right) \cdot \frac{\lg \left(\frac{d_{\text {angus }}}{75}\right)}{\lg 20}=0,973$} \\
\hline \multicolumn{5}{|c|}{$\kappa_{z}=1-0,2 \cdot \lg \left(\beta_{\text {paprate }}\right) \cdot \frac{\lg \left(\frac{d}{75}\right)}{\lg 20}=0,976$} \\
\hline$\beta_{\mathrm{se}}$ & $\begin{array}{l}\text { Faktor lokasi kritis } \\
\text { puntir }\end{array}$ & 1994 & & $\beta_{\text {kt }}=\beta_{\text {kaprate }} \cdot \frac{K_{\text {aqurste }}}{K_{a}}$ \\
\hline $\mathrm{K}_{2}$ & Faktor geometri & 0.91 & & $K_{g}=1-0,2 \frac{\lg \left(\frac{d}{7.5}\right)}{\lg 20}$ \\
\hline $\mathrm{K}_{y}$ & Faktor periakuan pands & 1.2 & & Tumpa perialuam \\
\hline $\mathrm{K}_{\mathrm{Db}}$ & $\begin{array}{l}\text { Faktor konsentrasi } \\
\text { bengkok }\end{array}$ & 2.03 & & $\kappa_{\mathrm{mb}}=\left(\frac{\beta_{\mathrm{lat}}}{K_{g}}+\frac{1}{K_{\mathrm{Dg}}}-1\right) \cdot \frac{1}{K_{y}}$ \\
\hline $\mathrm{K}_{\mathrm{Dx}}$ & $\begin{array}{l}\text { Faktor konsentrasi } \\
\text { puntir }\end{array}$ & 2.26 & & $K_{D t}=\left(\frac{\beta_{2 x t}}{K_{g}}+\frac{1}{K_{s t}}-1\right) \cdot \frac{1}{K_{v}}$ \\
\hline$\sigma_{\mathrm{b} E w}$ & \multirow{2}{*}{ Kemampuan bahan } & 277.13 & \multirow{2}{*}{$\frac{\mathrm{N}}{\mathrm{mm}^{2}}$} & $\sigma_{\mathrm{mCW}}=\frac{\sigma_{\mathrm{gWW}} \cdot K_{\mathrm{t}}}{K_{\mathrm{ab}}}$ \\
\hline$\tau_{n=0}$ & & 160.69 & & $\tau_{\text {taW }}=\frac{T_{\text {thWK }} \cdot K_{t}}{K_{\text {IIt }}}$ \\
\hline$S_{D}$ & Sqfety Factor Dinamis & 4.74 & & 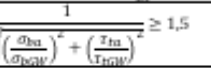 \\
\hline
\end{tabular}

Analisis Tegangan Roda Gigi dengan Solidworks

Untuk memastikan perhitungan manual yang telah dilakukan maka perlu dilakukan validasi menggunakan software analisis. Pada penelitian ini, penulis menggunakan software Solidworks 2016 untuk melakukan validasi terhadap tegangan kaki gigi pada roda gigi yang ada dalam gearbox yang penulis rancang. Berikut adalah salah satu contoh analisis roda gigi dengan software Solidworks 2016.

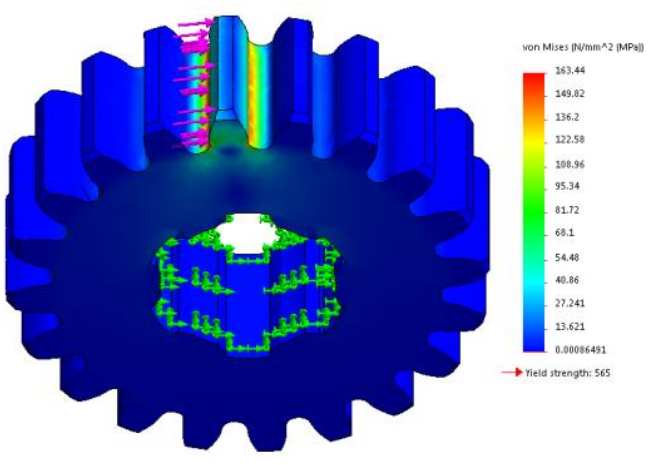

\section{Gambar 7 Analisis Finite Element dengan Solidworks}

Gambar 7 merupakan hasil dari analisis roda gigi dengan bahan $\mathrm{C} 45 \mathrm{E}$ dengan ukuran meshing 1.5 $\mathrm{mm}$. pada gambar tersebut diperoleh hasil tegangan maksmimum sebesar $163.44 \mathrm{~N} / \mathrm{mm}^{2}$ dan tegangan minimum sebesar $0.00086 \mathrm{~N} / \mathrm{mm}^{2}$

\section{Analisis dengan Software Kissoft}

- $\quad$ Roda Gigi

Analisis dengan menggunakan software Kissoft dilakukan untuk memvalidasi hasil perhitungan manual yang telah dilakukan. Berikut adalah hasil dari analisis kissoft pada salah satu roda gigi yang ada di dalam gearbox.

\section{Tabel 12 Perhitungan Roda Gigi Manual vs} Kissoft

\begin{tabular}{ccccc}
\hline \multicolumn{5}{c}{ Roda Gigi 1 } \\
\hline $\begin{array}{c}\text { Tegangan Kaki } \\
\text { Gigi (SF) }\end{array}$ & $\begin{array}{c}\text { Tekanan } \\
\text { Permukaan Kaki } \\
\text { Gigi (SH) }\end{array}$ & Keterangan \\
Manual & Kissoft & $\begin{array}{c}\text { Manual } \\
\text { Kissoft }\end{array}$ \\
$\mathbf{3 . 5 7}$ & 1.73 & 1.56 & 0.81 & $S F_{\text {min }} \geq 1$ \\
& & & $S H_{\text {min }} \geq 1$ \\
\hline
\end{tabular}

- Poros

Sama halnya dengan roda gigi, perhitungan poros juga perlu divalidasi, berikut adalah hasil analisisnya yang terdata pada gambar 8 .

19 Ibrahim, Bustami., dkk; Perancangan Gearbox Traktor Tangan 2 Kecepatan 1 Mundur Dengan Sistem Pemindah Gigi Synchromesh 


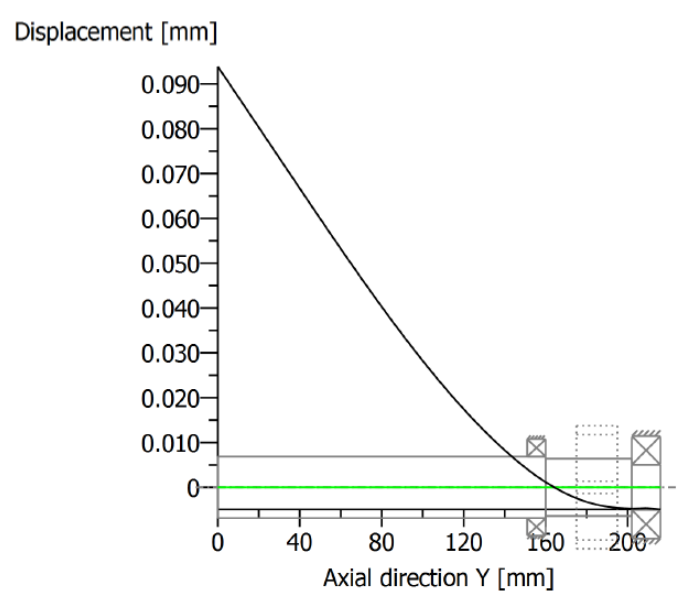

\section{Gambar 8 Hasil Defleksi Bengkok dengan Software Kissoft}

Tabel 13 dan gambar 9 adalah perbandingan hasil defleksi di lokasi roda gigi 1 berada :

\section{Tabel 13 Perbandingan Hasil Defleksi}

\begin{tabular}{cc}
\hline Manual & Kissoft \\
\hline $\mathbf{0 . 0 4} \mathbf{~ m m}$ & $0.07 \mathrm{~mm}$ \\
\hline
\end{tabular}

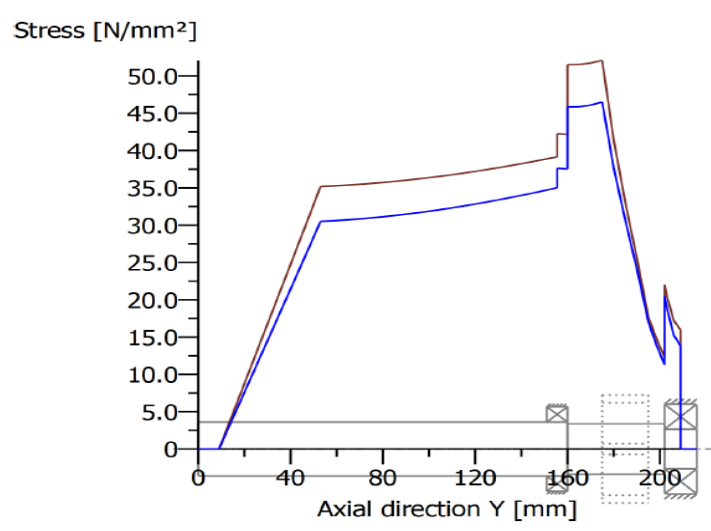

Gambar 9 Hasil Tegangan dengan Software Kissoft

Tabel 14 adalah perbandingan hasil tegangan di lokasi roda gigi 1 berada.

\section{Tabel 14 Perbandingan Hasil Tegangan}

\begin{tabular}{cc}
\hline Manual & Kissoft \\
\hline $\mathbf{3 6 . 6 ~ N} / \mathbf{m m}^{\mathbf{2}}$ & $35 \mathrm{~N} / \mathrm{mm}^{2}$ \\
\hline
\end{tabular}

\section{KESIMPULAN}

Dari rancangan gearbox yang dihasilkan dapat disimpulkan bahwa gearbox pada tugas akhir ini dirancang dalam tiga tingkatan transmisi dengan layout multi stage gearbox. Untuk sistem pemindah giginya, digunakan mekanisme gabungan dog clutch dan cone clutch atau synchromesh untuk menghasilkan pemindahan yang lebih halus.. Serta, gearbox yang dihasilkan memiliki berat $145 \mathrm{~kg}$, dengan dimensi total 310 × 640 × $648 \mathrm{~mm}$, dan jarak antara poros input - output sebesar $403.5 \mathrm{~mm}$. Selain itu, tuntutan kecepatan yang diinginkan pada gearbox ini dapat terpenuhi sesuai dengan daftar tuntutannya.

\section{DAFTAR PUSTAKA}

[1] [Chawathe, D.D. 2001. Handbook of Gear Technology. New Delhi: New Age International (P) Ltd.

[2] Hillier, V. A. dan Peter Coombes. 2004. Hillier's Fundamental of Motor Vehicle Technology (5th ed.). United Kingdom: Nelson Thornes Ltd.

[3] Jänsch, J. dan H. Birkhofer. 2006. "The Development of The Guideline VDI 2221 - The Change of Direction." International Design Conference - Design 2006. Dubrovnik - Croatia.

[4] Liljedahl, John B., dkk. 1989. Tractors and Their Power Units (4th ed.). New York: Van Nostrand Reinhold.

[5] Maitra, Gitin M. 1994. Handbook of Gear Design (2nd ed.). New Delhi: McGraw-Hill.

[6] Nauheimer, Harald., dkk. 2011. Automotive Transmission (2nd ed.). New York: Springer.

[7] Pahl, G. dan W. Beitz. 2005. Engineering Design (5th ed.). London: Springer-Verlag.

[8] Sularso dan Kiyokatsu Suga. 2002. Dasar Perencanaan dan Pemilihan Elemen Mesin. Jakarta: PT. Pradnya Paramita.

[9] Wittel, Herbert., dkk. 2013. Roloff/Matek Machinenelemente (21st ed.). Germany: Springer Vieweg.

[10]Zongxuan Sun dan Guoming Z. Zhu. 2015. Design and Control of Automotive Propulsion Systems. Boca Raton: Taylor \& Francis Group, LLC. 